\title{
A STUDY OF THE VOLUME OF THE BLOOD IN CONGESTIVE HEART FAILURE. RELATION TO OTHER MEASURE- MENTS IN FIFTEEN PATIENTS
}

\author{
By GEORGE R. MENEELY ${ }^{1}$ AND NOLAN L. KALTREIDER \\ (From the Department of Medicine of the School of Medicine and Dentistry of the University \\ of Rochester and the Medical Clinics of Strong Memorial and Rochester Municipal \\ Hospitals, Rochester, New York)
}

(Received for publication November 10, 1942)

While the volume of the blood in health is quite constant and closely related to the size, age, and sex of the individual, it has long been recognized that in congestive heart failure, this relationship is disturbed. Therefore, investigations of the volume of the blood in this clinical condition should throw light on the mechanism of normal control of the volume of the blood as well as on the nature of the physiological disturbances involved in heart failure itself. Studies of this nature, summarized by Gibson and Evans (1), indicate that there is an increase in the volume of the blood in this condition. While this generality is well supported, there is a striking variability in individual cases. It appeared likely that this variability might be accounted for if quantitative measurement of factors which might influence blood volume were made at the time of the determination of the blood volume. Since the association between anoxemia and compensatory polycythemia is well established, measurements of arterial and venous oxygen were made and it proved possible to show a rough quantitative relationship between anoxemia and cellular increase. On the other hand, while the statement has been made $(1,2)$ that there is a positive relationship between the venous pressure and the change in blood volume in congestive heart failure, it was not possible to find such a relationship within this group of severely congested cardiac patients.

Although a number of the lines of investigation pursued did not lead to the establishment of any simple correlation with plasma or cell volume changes, these data presented are of interest, not only in themselves, but also because certain interesting relations obtain between them. The results of these studies conducted on cardiac patients are therefore presented in full.

1 Louisiana State University School of Medicine, New Orleans, La.
MATERIAL

Fifteen patients were selected who had clinical evidence of severe congestive heart failure (class IV). All were dyspneic or orthopneic, all but one had pitting edema, all but one had hepatomegaly, most had chronic passive congestion of the lungs, a few had hydrothorax, several had ascites. The clinical findings in these patients are summarized in Table I. Every effort was made to select uncomplicated cases, who were untreated, or who were in a steady state despite digitalis. Etiology of the heart disease in these cases included rheumatic heart disease, arteriosclerosis, hypertension, thyrotoxicosis, syphilis, and heart disease secondary to pulmonary disease. The duration of failure ranged from a few weeks to several years. Patient number seven had evidence of a moderate degree of renal insufficiency and he also had hemoptysis. None of the others had evidence of chronic blood loss. Five patients were female and ten were male. The average age was 54.2 years, with one subject in the third decade, five in the fourth decade, four in the fifth, and five in the sixth decades.

\section{METHODS}

The patient was brought to the laboratory in bed in the post-absorptive state. The bed was adjusted to as flat a position as the subject could tolerate, and he was allowed to rest in this position for more than thirty minutes. Then the blood volume was determined by the method of Gibson and Evans (3). Predictions of blood, plasma, and cell volumes, normal for these patients were based on Gibson and Evans data (4), using the height of the subject, because edema rendered the weight an unsatisfactory reference value. Predicted values were subtracted from observed values, and the difference expressed as a percentage of the normal.

The same venipuncture made for the injection of the dye was used to determine the arm to tongue circulation time (5) and the venous pressure (6). The venous pressures were referred to a point six centimeters below the Angle of Louis. A period of rest followed, then samples of blood were taken from the radial artery and the antecubital vein simultaneously in oiled syringes and stored over mercury with refrigeration. Dry potassium oxalate was used as the anti-coagulant. The vital capacity was determined with a spirometer, recording the best of three trials. Several hematocrit determinations were made by the wet technique of Gibson (3), using 1.6 per cent potas- 
.

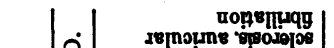

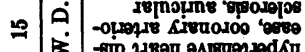

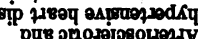

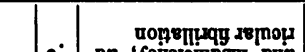

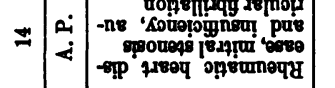

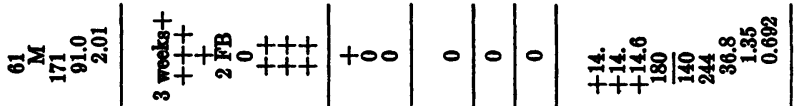

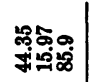

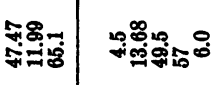

O)

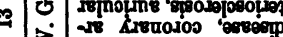

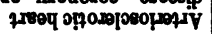

ณ조엉

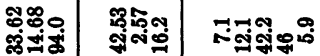

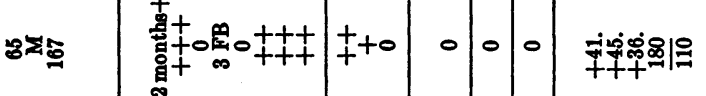

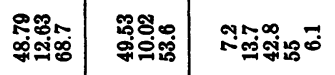

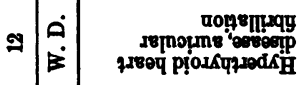

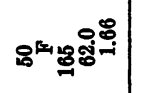

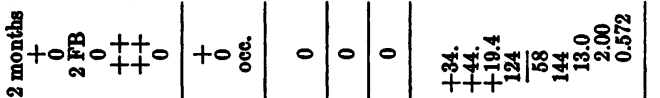

คำำ

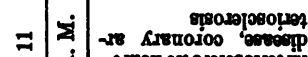

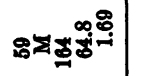

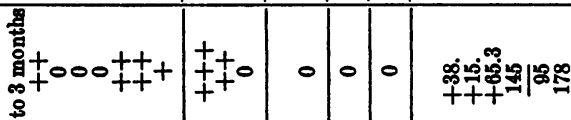

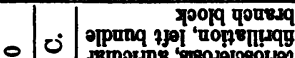

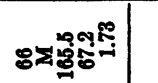

$\begin{array}{llll}0 & 1 & 1\end{array}$

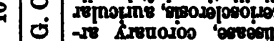

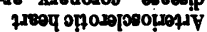

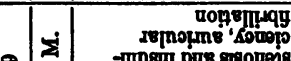

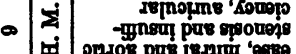

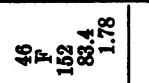

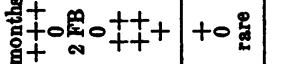

พ่า่ํํำ

1

1

15) $\infty$. I.

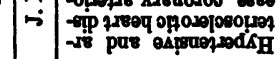

수요

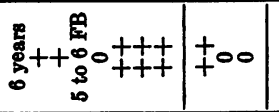

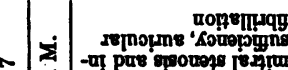

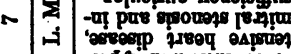

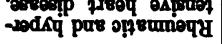

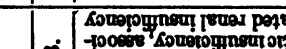

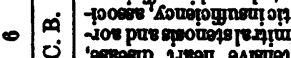
- IOdKप pus ops

พ⿻ำ

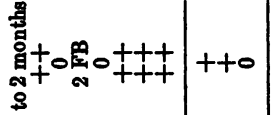

0.0

+十+⿴囗十

$=$ พ⿻ำ

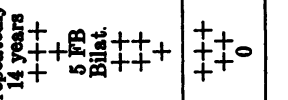

常熙。

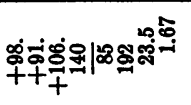

జ్రం

mo

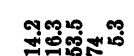

- Solorpgnnsut onjor

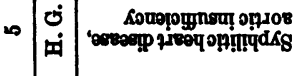

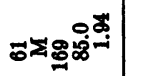

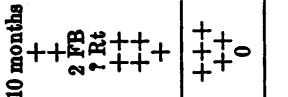

当突息

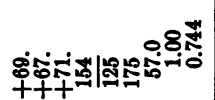

\$ำำ

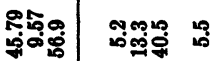

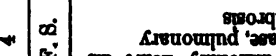

도유.

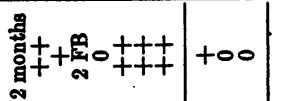

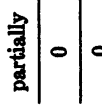

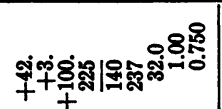

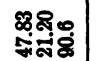

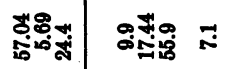

$\delta$

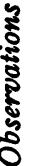

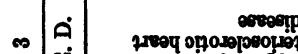

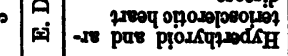

कำ

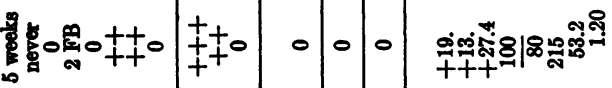

†ำ

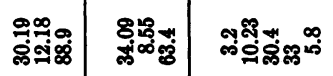

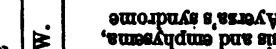

- 1 -

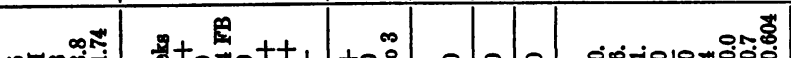

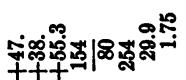

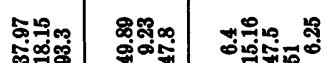

अ충ำ-

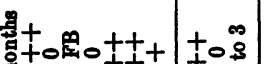

苜

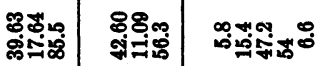

|

สำ

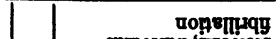

$-\begin{array}{ccc}0 \\ 0 \\ 0\end{array}$

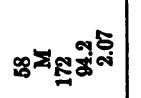

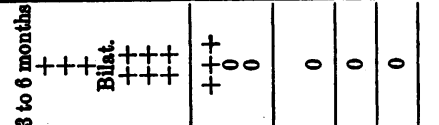

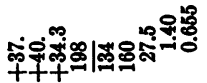

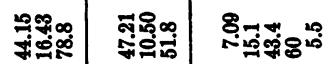

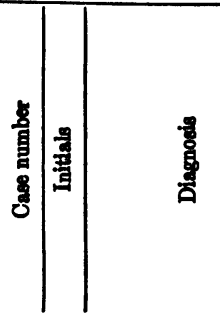

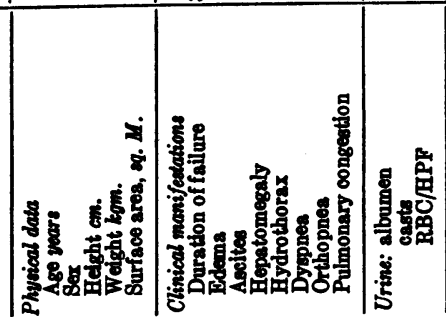

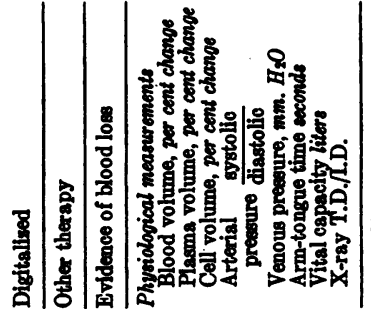

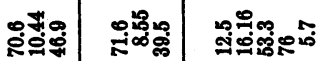


TABLE II

Determinations repeated after clinical change

\begin{tabular}{|c|c|c|c|c|c|c|c|c|}
\hline Patient number & \multicolumn{2}{|c|}{12} & \multicolumn{2}{|c|}{13} & \multicolumn{2}{|c|}{14} & \multicolumn{2}{|c|}{15} \\
\hline Sex & \multicolumn{2}{|c|}{$\mathbf{F}$} & \multicolumn{2}{|c|}{$\mathbf{M}$} & \multicolumn{2}{|c|}{$\mathbf{M}$} & \multicolumn{2}{|c|}{$\mathbf{M}$} \\
\hline Clinical change & \multicolumn{2}{|c|}{ Improved } & \multicolumn{2}{|c|}{ Improved } & \multicolumn{2}{|c|}{ Worse } & \multicolumn{2}{|c|}{ Improved } \\
\hline Interval between determinations & \multicolumn{2}{|c|}{18 days } & \multicolumn{2}{|c|}{13 days } & \multicolumn{2}{|c|}{6 days } & \multicolumn{2}{|c|}{4 days } \\
\hline $\begin{array}{l}\text { Venous pressure, mm. of } \mathrm{H}_{2} \mathrm{O} \\
\text { Arm to tongue time, seconds } \\
\text { Vital capacity, liters } \\
\text { Arterial } \mathrm{O}_{2} \text { saturation, per cent } \\
\text { Venous } \mathrm{O}_{2} \text { saturation, per cent } \\
\text { Capillary unsaturation, volumes per cent } \\
\text { Hemoglobin, grams } \\
\text { Volume packed red cells, per cent } \\
\text { Plasma proteins, grams per cent } \\
\text { Blood volume, per cent change } \\
\text { Cell volume, per cent change } \\
\text { Plasma volume, per cent change } \\
\text { Weight, } \text { kgm. }\end{array}$ & $\begin{array}{r}144 \\
13 \\
2.0 \\
92.5 \\
75.0 \\
2.5 \\
12.3 \\
35.4 \\
5.7 \\
+34 \\
+19 \\
+44 \\
62\end{array}$ & $\begin{array}{r}107 \\
13 \\
2.6 \\
92.5 \\
60.0 \\
3.9 \\
12.5 \\
38.9 \\
6.2 \\
+21 \\
+18 \\
+23 \\
57\end{array}$ & $\begin{array}{r}68.7 \\
53.6 \\
7.2 \\
13.7 \\
43.2 \\
6.1 \\
+41 \\
+36 \\
+45\end{array}$ & $\begin{array}{r}64 \\
\\
90.3 \\
60.6 \\
5.2 \\
16.3 \\
47.0 \\
6.8 \\
+21 \\
+27 \\
+16\end{array}$ & $\begin{array}{r}109 \\
26 \\
2.9 \\
97.1 \\
62.3 \\
3.6 \\
13.8 \\
46.5 \\
6.8 \\
+8 \\
+13 \\
+4 \\
56\end{array}$ & $\begin{array}{r}270 \\
35 \\
2.5 \\
94.0 \\
16.2 \\
7.1 \\
12.1 \\
42.2 \\
5.9 \\
+25 \\
+19 \\
+31 \\
62\end{array}$ & $\begin{array}{c}244 \\
37 \\
1.4 \\
85.9 \\
65.1 \\
4.5 \\
13.7 \\
44.8 \\
6.0 \\
+14 \\
+15 \\
+14 \\
91\end{array}$ & $\begin{array}{c}114 \\
33 \\
1.7 \\
91.4 \\
70.7 \\
4.2 \\
17.4 \\
51.8 \\
4.7 \\
-8 \\
+7 \\
-20 \\
79\end{array}$ \\
\hline
\end{tabular}

sium oxalate. The arterial blood pressure and the height and weight were determined.

Analyses of the blood samples for oxygen and carbon dioxide content and oxygen combining power were made (7) and the hemoglobin content calculated. Capillary unsaturation was calculated from Lundsgaard's (8) formula $\frac{A+V}{2}$ where $A$ and $V$ are the arterial and venous unsaturation respectively. The carbon dioxide combining power (9) and the plasma total protein (micro-Kjeldahl) were determined. In nine patients, satisfactory teleoroentgenograms of the heart were taken. These were measured to obtain the internal diameter of the chest at the level of the fourth costochondral junction and for transverse diameter of the heart, taking the horizontal distance from the outermost right to the outermost left border. The ratio of the transverse diameter of the heart to the internal diameter of the chest was calculated.

The data obtained are presented in Table I. In several of the patients, the whole procedure was repeated after a clinical change in the patient, and the relevant data showing these changes are presented in Table II.

\section{RESULTS}

The blood volume was increased in all cases and in the great majority, the increase was substantial. The mean increase over predicted was $46 \pm 27^{2}$ per cent. The plasma volume was increased with a mean of $44 \pm 27^{2}$ per cent for the group as was the cell volume with a mean of 48 $\pm 43^{2}$ per cent. While the mean increase in the cell volume is greater than the increase in the plasma volume, in the light of the variability

2 One standard deviation not corrected for small size of sample. within the group, there is no statistical significance in the difference between these means. Even when the more sensitive comparison in each individual case is made, the mean difference between the cell volume and the plasma volume is only plus 5.5 per cent. This mean is not significantly different from zero by Fisher's method of $t$ (11).

The mean of the venous pressures of the group is $203 \pm 45^{2} \mathrm{~mm}$. of water in the fourteen cases where measurements were made. In nearly all the cases, right upper quadrant pressure for about ten seconds produced a rise in venous pressure. This test has often been discussed in connection with congestive heart failure, but in this study, it was performed primarily for the purpose of assuring a free connection between the manometer and the venous circuit.

The venous pressure was compared with the blood volume, the plasma volume, and the cell volume, by graphic and statistical methods. (Figures 1 and 2 and Table III.) There is no significant correlation between the blood volume or the plasma volume and the venous pressure. The interpretation of this statement must be strict if it is to have meaning. These patients all suffer from severe congestive heart failure. If a group of cases ranging from normal through mild insufficiency to severe heart failure were studied, there would in all probability be a high correlation between venous pressure and the blood volume or plasma volume. The finding means simply that 
within a group of patients with severe failure there is no correlation between venous pressure and blood volume or plasma volume. There is a negative correlation of moderate significance between the cell volume and the venous pressure.
The circulation time for the group is increased to a mean of $31 \pm 18^{2}$ seconds. Two patients (case number 3 and case number 12) had short circulation time from arm to tongue. Both of these had hyperthyroid heart disease. The cir-
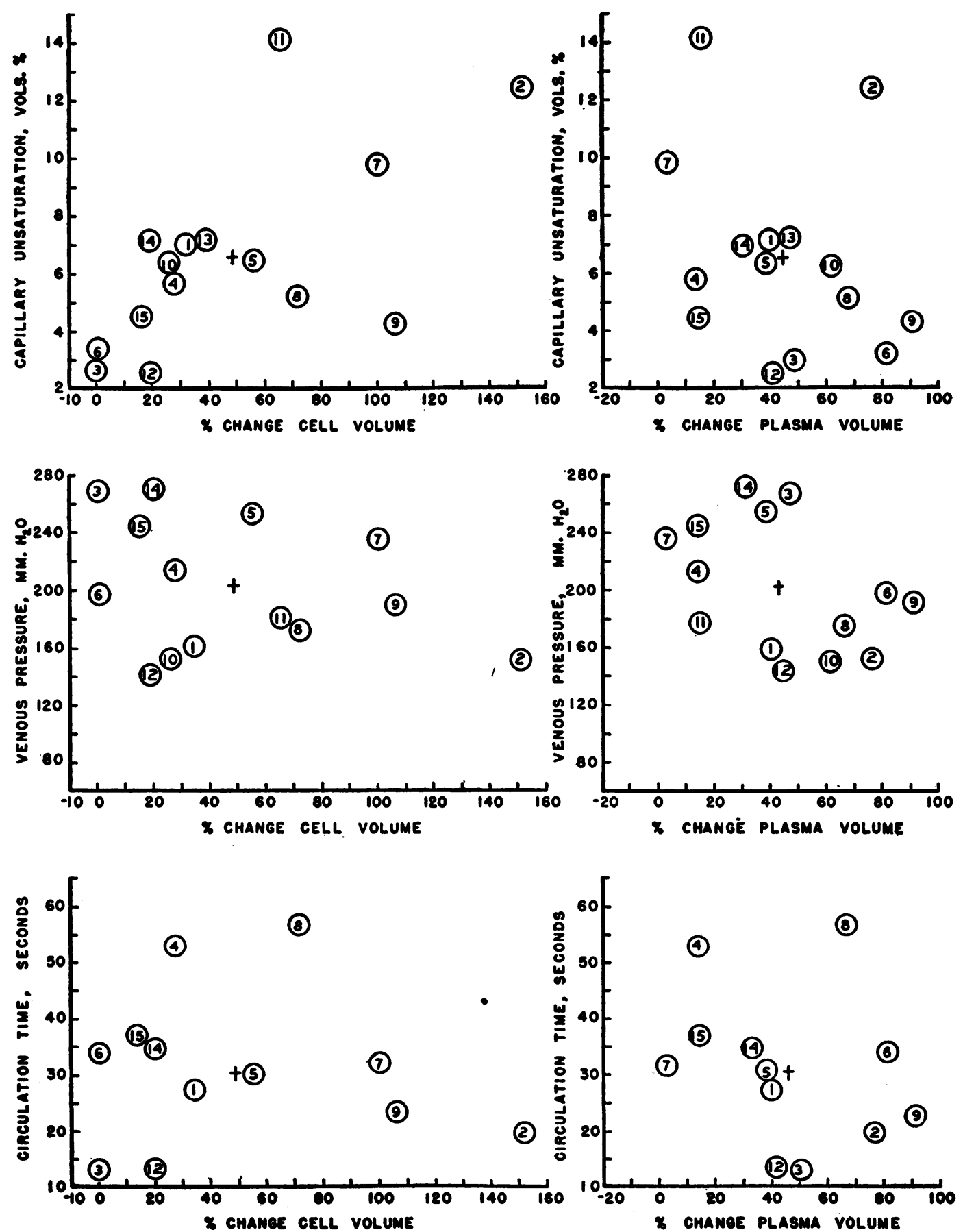

Fig. 1. Correlations Between Capillary Unsaturation, Venous Prfessure, and Circulation Time, and the Per Cent Change in the Blood Volume and Its Components in 15 Patients With Severe Congestive Heart Failure 

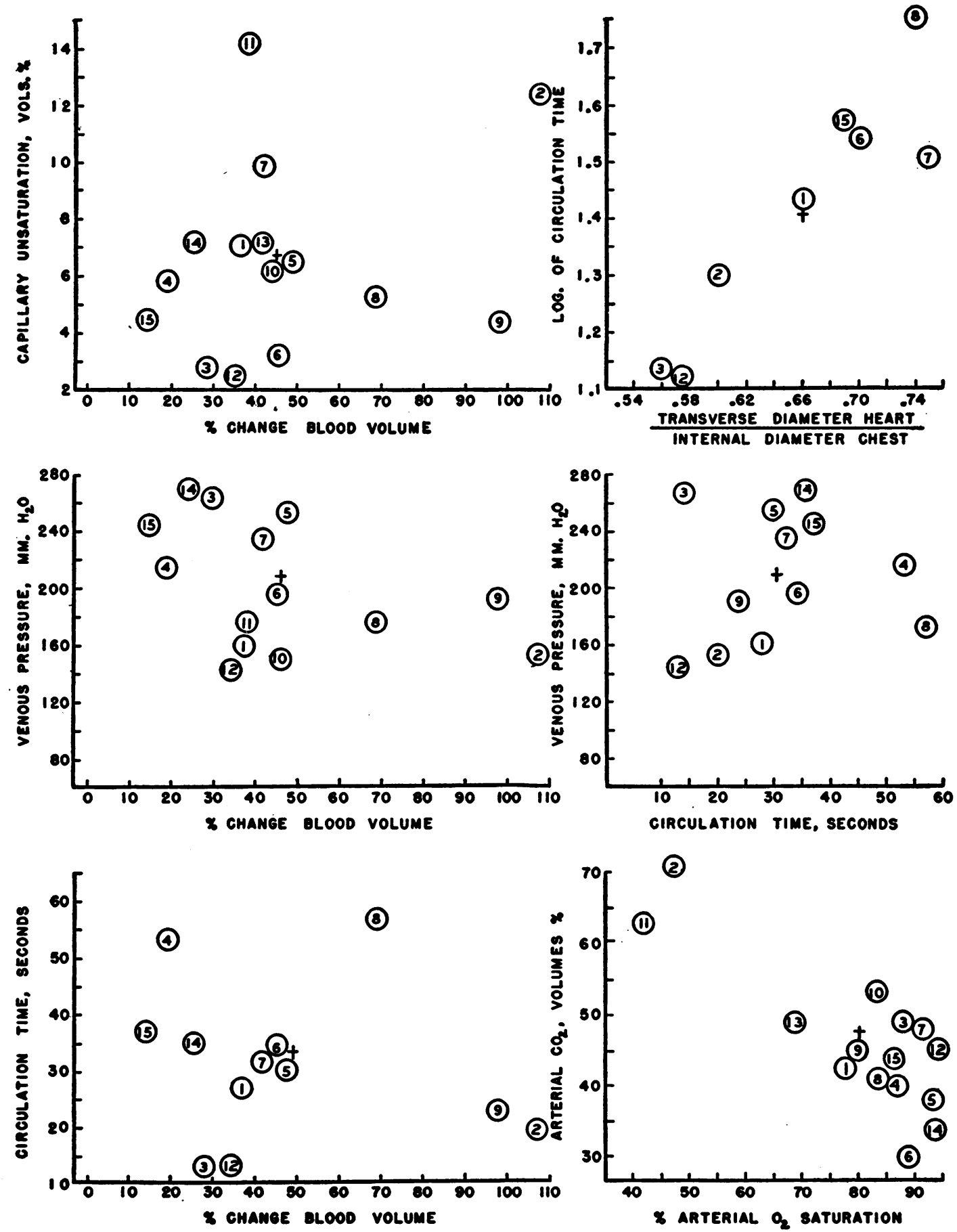

Fig. 2. Correlations Between Various Cardiovascular Measurements in 15 Patients With Severe Congestive Heart Failure

culation time was compared with the blood volume, plasma volume, and cell volume (Figures 1 and 2 and Table III). There is no simple relation, the coefficients of correlation all being nonsignificant. As in the case of the venous pressure, the interpretation must be strict: within a group of patients with severe heart failure, there is no simple relation between the blood volume or its fractions and the arm to tongue circulation time. Because both the venous pressure and the cir- 
culation time usually rise as congestive heart failure develops, it might be anticipated that there would be a simple relationship between these two. Within this group, such is not the case. There is no significant correlation between the venous pres-

TABLE III

Correlation between various measurements Coefficients italicized are significant

\begin{tabular}{|c|c|c|c|}
\hline Correlation & Cases & $\begin{array}{c}\text { Coeffi- } \\
\text { cient }\end{array}$ & $\begin{array}{l}\text { Significance } \\
(\mathbf{P}=)\end{array}$ \\
\hline 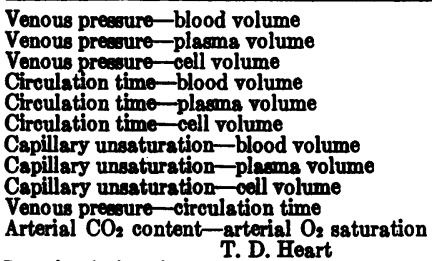 & $\begin{array}{l}14 \\
14 \\
14 \\
12 \\
12 \\
12 \\
15 \\
15 \\
15 \\
12 \\
15\end{array}$ & $\begin{array}{l}-0.418 \\
-0.400 \\
-0.645 \\
-0.105 \\
-0.199 \\
+0.231 \\
+0.264 \\
-0.257 \\
+0.680 \\
+0.099 \\
-0.826\end{array}$ & $\begin{array}{c}\text { no } \\
\text { no } \\
\text { leas than } 0.05 \\
\text { no } \\
\text { no } \\
\text { no } \\
\text { no } \\
\text { no } \\
\text { leas than } 0.02 \\
\text { no } \\
\text { lees than } 0.01\end{array}$ \\
\hline Log circulation time- $\frac{\text { I. D. Chest }}{\text { I. }}$ & 8 & +0.989 & lees than 0.01 \\
\hline
\end{tabular}

sure and the circulation time, another statement which must be interpreted strictly as applying to this group of patients.

The saturation of arterial blood with oxygen ranged from normal levels to the low level of 41.8 per cent. The majority of the patients, eleven in number, show values between 80 and 94 per cent saturation, which is the common range in heart failure. Only four patients show values above 90 per cent, indicating that most of these patients have anoxic anoxia in varying degree.

While venous blood from the antecubital vein does not represent true mixed venous blood, it is, when taken under standard conditions, a useful index. The venous oxygen saturations observed range from 75 per cent to the very low value of 16.2 per cent. This lowest venous oxygen saturation occurred in the individual (number 14) who had the highest arterial saturation, representing purely stagnant anoxia. However, for the most part, the subjects studied showed mixtures of the stagnant and the anoxic forms of anoxia.

The best formulation of the degree of anoxia available from the data obtained is the capillary unsaturation expressed by Lundsgaard (8), as mentioned above. The mean capillary unsaturation in this group was $6.6 \pm 3.4^{2}$ volumes per cent. Normal capillary unsaturation is 3.5 volumes per cent, and cyanosis appears at the level of 6.0 .
To determine the relation of anoxia to the blood volume, the capillary unsaturation was compared with the blood volume and its fractions. There was no significant correlation with total blood volume nor with plasma volume, but there was a highly significant correlation with cell volume. The coefficient of correlation between the cell volume and the capillary unsaturation was $+0.630 .^{3}$

The carbon dioxide content of the arterial blood covers a wide range, from marked degrees of retention to quite low values. Taking 42 to 54 volumes per cent as the normal range (10), there are five cases below this range and two above it. The patients with marked carbon dioxide retention (numbers 2 and 11) had associated, marked anoxia. Both these patients had primarily pulmonary disease.

The vital capacity in all cases was low, ranging from 2.5 liters to 0.7 liters. The patient with the highest vital capacity (number 14) had also the highest oxygen saturation, and the individual with the lowest (number 2) had the lowest arterial oxygen saturation, but among the others there is no relationship apparent.

In those patients where roentgenograms of the chest were taken, measurement of the heart showed that all had large hearts. In order to allow for variation in stature of the individuals, the ratio of transverse heart diameter to internal thoracic diameter is used rather than the size of the heart itself. In normal patients, measured as in this study, this ratio is usually well below 0.5 . It ranged in eight available cases between 0.564 and 0.750 with a mean of $0.66 \pm 0.07 .^{2}$ An interesting relation obtains between the T.D./I.D. ratio and the circulation time. A linear plot of pairs of data suggested an exponential relation and a highly significant correlation was found between the logarithm of the circulation time and the T.D./I.D. ratio with a coefficient of correlation of 0.929 .4

The hemoglobin concentration and the hematocrit give very little information with regard to

${ }^{8}$ A coefficient of correlation greater than 0.592 will occur in only two per cent of cases by chance with fifteen pairs of data. Fisher's Table V.A (11).

4 A coefficient of correlation greater than 0.834 will occur by chance in only one per cent of cases with nine pairs of data. Fisher (11). 
the actual volume of circulating blood or the absolute increase of either fraction. While the lowest values observed for volume of packed red blood cells occurs in those patients with the smallest change of total cell volume from normal, and while those patients with the largest volume of packed red cells had substantial increases, yet the correlation is very loose. Between the values of 40 and 45 volumes per cent of packed red cells there are five cases with red cell volumes ranging from normal to 106 per cent above predicted.

The plasma carbon dioxide combining power observed in these patients varies over a wide range from 33 volumes per cent to 76 volumes per cent. It is closely related to the arterial carbon dioxide content. There is no relation between the carbon dioxide content and the blood volume or its fractions within this group of patients.

Serum proteins averaged $5.91 \pm 0.47^{2}$ grams per cent, in the lower range, but not by any means in the range of edema production. The volume of the blood and its fractions bore no simple relation to the plasma proteins.

Three patients were studied after improvement of their condition had been observed clinically. Patient number 12 had little anoxia and very little increase in cell volume. As she improved, there was diminution of her blood volume, due entirely to reduction in plasma volume. In the other two, the blood volume also diminished but the cell volume shared in the reduction, although not to the same extent as the plasma volume.

Patient number 14 who became worse when therapy was withdrawn and salt and fluids given freely, showed essentially the opposite change. Blood volume increased due to an increase in both fractions but principally due to plasma increase. Hemodilution occurred. Capillary unsaturation doubled due to stagnation, although changes in this value had not been striking in the patients who improved.

\section{DISCUSSION}

The blood volume method described by Gregerson, Gibson, and Stead (12), using the blue dye T-1824 suggested by Dawson, Evans and Whipple (13), was adapted to clinical use by Gibson and Evans (3). It is thought to be more accurate than previous dye methods because of improved colorimetry, correction for hemolysis, allowance of adequate time for mixing, and correction for the disappearance of dye from the blood stream. Gibson and Evans found two-thirds of their normal patients had blood volumes within plus and minus 10 per cent of the average for their sex, and that predictions of greater accuracy could be made on the basis of sex and height (or surface area).

Freeman, Freedman, and Miller (14) found that under certain conditions, notably shock, the blue dye may escape from the blood stream, as evidenced by failure of the extrapolated dye line to check with subsequent determinations, steep slope of subsequent dye lines, and the presence of dye stained fluid in the tissue spaces, cisterna chyli, pericardial sac, and the lumen of the intestine. In the cases studied, there is no reason to believe that permeability of the vascular tree to the dye existed, because there was no unusual dye line slope and blue staining of transudates was never observed although many were examined. We concluded that determination of the plasma volume in these patients was as accurate as in Gibson and Evans' standard series, that is, better than 10 per cent in two-thirds of the cases studied.

More serious objection exists to the determination of the cell volume. Smith, Arnold, and Whipple (15) ascribed the lack of agreement between blood volume methods which depend on plasma volume measurements and those which depend on cell volume measurements to variation in the ratio of cells to plasma in different parts of the vascular tree. Ebert and Stead (16), by their bleeding experiments, have recently produced evidence that this is indeed the case as has Hahn (17), using radioactive red cells. It is evident, then, that in the absolute values reported for red cell volume, there is an error of unknown magnitude which arises from the assumption that the hematocrit ratios obtained with venous blood represent the average body hematocrit. However, the relative changes in the total cell volume probably are significant.

The blood volumes found in the nineteen cases studied were all above normal, and in 13 cases, the increase was over 20 per cent. This is in accord with the finding of Gibson and Evans $(1,2)$ that in congestive heart failure, patients with diminished blood volumes do not occur. It was 
not found, however, that there was any significant difference in the change in the two fractions. Great variability exists in the elevation of the blood volume itself, and in the plasma and cell volumes in the individual cases, although, in the majority, elevation of both components occurred.

Consideration of changes observed in the volume of the blood may well involve separate consideration of the two fractions, for there is evidence that control of the watery and of the cellular fractions of the blood are mediated in different ways.

Anoxemia has been considered as a factor in changes in hemoglobin and red cells since the work of Bert in 1882 (18), and Wintrobe and Harrop (19) have reviewed the hematologic effects of anoxemia. In brief, there is an increase in the circulating red cell volume in chronic anoxemia due to altitude, with an increased total blood volume, due largely to increase in the cells. Upon return to normal levels, the cell volume falls and there is a slight compensatory rise in the plasma volume. Compensatory polycythemia is thus a cellular affair, with essentially normal plasma volume. For reasons not understood, anoxemia does not always produce a polycythemia as noted by Kaltreider, Hurtado, and Brooks (20) and Lemon (21).

In heart disease, however, the change in the blood volume involves both fractions. From the work of Bolton (22), it would appear that the earlier change is in the plasma volume. It might be supposed that anoxemia does not become a factor until stagnation and pulmonary congestion produce it, and in the train of anoxemia, increased hematopoietic activity ensues.

There is increased hematopoietic activity in congestive heart failure: Weil in 1901 (23) and Fromherz in 1903 (24) noted virtual replacement of the yellow marrow by red in polycythemic congenital cardiac patients. Waller and Blumgart (25) showed a definite reticulocytosis, diminished excretion of urobilin, and increased red cell mass before congestive heart failure becomes advanced. With onset of clinical improvement, when reduction of the total blood volume ensues, the red cells undergo hemolysis (due in part to the observed increased fragility), the level of bilirubin in the blood rises, the excretion of urobilinogen increases, and the reticulocyte percentage becomes smaller.

From these findings and the data reported above, it appears that the cellular portion of the blood responds to the observed anoxemia in heart failure according to the degree in which it is present, due to increase or decrease in hematopoietic activity and changes in blood destruction as the patient becomes more or less anoxemic. More satisfactory formulation of the degree of anoxemia than the "capillary unsaturation" should show a closer relation, for it is well recognized that it is the oxygen tension, not the concentration, which is of primary importance.

Nothing in the data accumulated bears a simple relation to the plasma volume. It does not correlate with circulation time, anoxemia, plasma carbon dioxide combining power, nor plasma proteins. It is more labile than the cell volume as evidenced by the four repeated studies, a phenomenon observed by Gibson and Evans (1) who noted the more rapid decline of the plasma volume with clinical improvement, but also a subsequent cell volume decline.

The negative correlation observed between the venous pressure and the cell volume within this group of patients is difficult to understand. Survey of a group of patients such as Gibson's (1) shows general rise of the blood volume and its fractions with rising venous pressures. Despite the statistical indication of probable significance, it is most likely an artificial result of selection of these patients, who all had elevated venous pressures; for in other factors studied, a better distribution over the range from normal to marked abnormality was obtained. Conceivable, however, is the hypothesis that if the elevation of venous pressure is compensatory, then in those who respond less well, more anoxemia occurs and hence greater hematopoietic stimulation. In the interpretation of these results, it is important to remember that these correlations were derived from a very limited series of patients, suffering from severe congestive heart failure. It would appear that the control of the plasma volume in severe congested cardiacs is mediated by mechanisms not studied in this group of patients.

The role of the blood volume in the complete picture of congestive heart failure remains obscure. From the known response of the cell volume and the hematopoietic system as a whole to anoxemia, and from the observed parallelism of increasing cell volume with increasing grades of anoxe- 
mia, the contribution of the cell volume to the increased blood volume of congestive heart failure is comprehensible. It appears likely, however, that the changes in the plasma volume are primary to the changes in cell volume, because the plasma volume is more labile, because heart failure is at least moderately advanced before anoxemia of any significant degree obtains, and because rise of the plasma volume occurs first in experimental congestion. The data obtained and the analyses made do not shed light upon the question of whether the increased blood volume is the result of the increase in venous pressure or the cause of it.

Failure of the venous pressure to correlate with the circulation time is at variance with the general experience that as heart failure advances, the circulation time and the venous pressure both increase. Two factors appear to contribute to the observations made here: first, the selection only of severely congested cardiacs, and second, the impossibility of evaluation of right versus left heart failure from the data obtained.

Most interesting is the relation between the circulation time and the transverse diameter of the heart. First mention of this relation appears in the French literature in the work of David and Bouvrain (26). Since there are only nine cases observed in this study, it is not advisable to speculate upon this relationship until further study adds a larger amount of data.

The plasma protein values found agree with the generally accepted view that in heart failure, the proteins are lower than normal, but not lowered to a degree sufficient to produce edema. Interpretation of the significance of plasma proteins in heart failure should only be made in the light of the state of fluid balance of the patient, according to Stewart (27), and as these patients were not followed in this regard, no comment should be made upon the proteins.

\section{SUMMARY AND CONCLUSIONS}

1. In fifteen patients with severe congestive heart failure, the blood volume, arterial and venous blood pressure, arm to tongue circulation time, vital capacity, arterial and venous oxygen and carbon dioxide content and oxygen combining power, volume of packed red cells, plasma carbon dioxide combining power, and plasma total proteins were measured and are reported.

2. The blood volume was increased in all cases, and in most, the increase was substantial.

3. There was great variability in the increase and in the degree to which the plasma and the cells contributed to the increase, and no statistically significant difference was observed between the increase in cell and plasma volume.

4. There was no simple correlation between the total blood volume and the other measurements made, nor between the venous pressure and the circulation time.

5. A negative correlation of moderate significance was found between the venous pressure and the plasma volume.

6. The logarithm of the circulation time bore a linear relation to the ratio between the transverse diameter of the heart and the internal diameter of the chest in eight cases where roentgenograms of the chest were taken.

7. The venous hematocrit and hemoglobin gave little indication of the actual volume of circulating cells.

8. There was a highly significant correlation between the degree of anoxemia measured by Lundsgaard's "capillary unsaturation" and the increase in cell volume.

9. In three patients who improved, all measurements tended towards normal, the plasma volume decreasing more than the cell volume. In the patient who grew worse, the reverse was the case.

\section{BIBLIOGRAPHY}

1. Gibson, J. G., Jr., and Evans, W. A., Jr., Clinical studies of the blood volume. III. Changes in blood volume, venous pressure, and blood velocity rate in chronic congestive heart failure. J. Clin. Invest., 1937, 16, 851.

2. Gibson, J. G., Jr., The clinical significance of the blood volume. Ann. Int. Med., 1941, 14, 2014.

3. Gibson, J. G., Jr., and Evans, W. A., Jr., Clinical studies of the blood volume. I. Clinical application of a method employing the azo dye "Evans blue" and the spectrophotometer. J. Clin. Invest., 1937, 16, 301.

4. Gibson, J. G., Jr., and Evans, W. A., Jr., Clinical studies of the blood volume. II. The relation of the plasma and total blood volume to venous pressure, blood velocity rate, physical measurements, age, and sex in ninety normal humans. J. Clin. Invest., 1937, 16, 317 . 
5. Winternitz, M., Deutsch, J., and Brüll, Z., Eine klinisch brauchbare Bestimmungsmethode der Blutumlaufszeit mittels Dekholininjection. Med. Klin., 1931, 27, 986.

6. Griffith, G. C., Chamberlain, C. T., and Kitchell, J. R., A simplified apparatus for direct venous pressure determination modified from Moritz and v. Tabora. Am. J. M. Sc., 1934, 187, 371.

7. Vari Slyke, D. D., and Neill, J. M., The determination of gases in blood and other solutions by vacuum extraction and manometric measurement. J. Biol. Chem., 1924, 61, 523.

8. Lundsgaard, C., Studies on cyanosis. I. Primary cause of cyanosis. J. Exper. Med., 1919, 30, 259.

9. Van Slyke, D. D., and Cullen, G. E., Studies of acidosis. I. The bicarbonate concentration of the blood plasma; its significance and its determination as a measure of acidosis. J. Biol. Chem., 1917, 30, 289.

10. Peters, J. P., and Van Slyke, D. D., Quantitative Clinical Chemistry. Williams and Wilkins, Baltimore, 1931.

11. Fisher, R. A., Statistical Methods for Research Workers. Oliver and Boyd, London, 1938

12. Gregerson, M. I., Gibson, J. G., Jr., and Stead, E. A., Plasma volume determination with dyes; errors in colorimetry; use of the blue dye T-1824. Am. J. Physiol., 1935, 113, 54.

13. Dawson, A. B., Evans, H. M., and Whipple, G. H., Blood volume studies. III. Behavior of a large series of dyes introduced into the circulating blood. Am. J. Physiol., 1920, 51, 232.

14. Freeman, N. E., Freedman, H., and Miller, C. C., Production of shock by prolonged continuous injection of adrenalin in unanaesthetized dogs. Am. J. Physiol., 1941, 131, 545.

15. Smith, H. P., Arnold, H. R., and Whipple, G. H., Blood volume studies, VII. Comparative values of Welcker, $\mathrm{CO}$, and dye methods for blood volume determinations. Accurate estimation of the absolute blood volume. Am. J. Physiol., 1921, 56, 336.
16. Ebert, R. V., and Stead, E. A., Jr., Demonstration that the cell plasma ratio of blood contained in minute vessels is lower than that of venous blood. J. Clin. Invest., 1941, 20, 317.

17. Hahn, P. F., et al., Red cell volume circulating and total as determined by radio iron. Science, 1941, 93, 87.

18. Bert, $P$., Sur la richesse en hémaglobine du sang des animaux vivant sur les haut lieux. Compt. rend. Acad. d. sc., 1882, 94, 805.

19. Harrop, G. A., and Wintrobe, M. M., Polycythemia. Handbook of Hematology, H. Downey, Editor. P. B. Hoeber, Inc., New York, 1938.

20. Kaltreider, N. L., Hurtado, A., and Brooks, W. D. W., Study of the blood in chronic respiratory diseases, with special reference to the volume of the blood. J. Clin. Invest., 1934, 13, 999.

21. Lemon, W. S., A study of the effect of chronic pulmonary diseases on the volume and composition of the blood. Ann. Int. Med., 1929, 3, 430.

22. Bolton, C., The pathology of cardiac dropsy. Brit. M. J., 1917, 1, 642 ; and ibid., 678.

23. Weil, E., Note sur les organes hématopoietiques et l'hématopoièse dans la cyanose congénitale. Compt. rend. Soc. d. biol., 1901, 53, 713.

24. Fromherz, E., Zur Bedeutung der Hyperglobulie bei kongenitalen Herzkrankheiten. München. med. Wchnschr., 1903, 1, 1718.

25. Waller, J. V., Blumgart, H. L., and Volk, M. D., Studies of the blood in congestive heart failure, with particular reference to reticulocytosis, erythrocyte fragility, bilirubinemia, urobilinogen excretion, and changes in blood volume. Arch. Int. Med., 1940, 66, 1230.

26. David, C., and Bouvrain, Y., Contribution à l'étude physiopathologique de la vitesse de circulation. Arch. d. mal. du coeur, 1940, 33, 147.

27. Stewart, H. J., Mechanism of diuresis : Alterations in the specific gravity of the blood plasma with onset of diuresis in heart failure. J. Clin. Invest., 1941, $20,1$. 